\title{
Flexural Behaviour of Precast, Prestressed Ribbed RPC Bottom Panels
}

\author{
Zheng Wenzhong*, Lu Xueyuan and Wang Ying \\ Key Lab of Structures Dynamic Behavior and Control of the Ministry Education, Harbin Institute of Technology, Harbin \\ 150090, P.R. China
}

\begin{abstract}
This study introduces a new type of precast, prestressed reactive powder concrete (RPC) bottom panel for a large-span composite slab. The bottom panels, which have one or two inverted ribs with openings, act as formwork during the construction stage. The paper experimentally investigated the crack characteristics, deflection, and normal section bearing capacity of four precast, prestressed ribbed RPC bottom panels under flexural load. The results indicated that the RPC ultimate strain under non-uniform compression is $5500 \times 10^{-6}$ and the plastic influence coefficient of the section modulus is linear with the longitudinal reinforcement ratio. The tensile stress of RPC at the cracked section should be considered while calculating the flexural stiffness; the equation used to determine the nominal tensile stress of RPC as a major variable for calculating the crack width at the bottom of panels was proposed. The bottom panels generally exhibit an over-reinforced failure mode behaviour without the composite layer; the calculation method of the normal section bearing capacity of this mode was established.
\end{abstract}

Keywords: Crack width, flexural stiffness, normal section bearing capacity, precast, prestressed ribbed RPC bottom panel, reactive powder concrete.

\section{INTRODUCTION}

The composite slab is a semi-fabricated system that consists of a precast bottom panel and a composite layer. The precast bottom panel acts as formwork during the construction stage and then forms an integral part of the composite layer after the solidification of cast-in-place concrete. Compared with cast-in-place slabs, composite slabs have the advantages of low cost, rapid construction and improved quality control, which have led to its widespread application throughout the world [1]. To improve the integrity of the two layers, a precast bottom panel with rough surfaces $[2,3]$ or with lattice steel truss projects at the top [4-6] can be used. Precast bottom panels with a rough surface are easy to produce but have small spans. Precast bottom panels with lattice steel truss projects at the top have better integrity and larger spans; however, steel trusses are expensive if they are applied in large spans. To overcome these problems, Jiang Qingqing [7] proposed a precast bottom slab with an inverted rib that has better flexural stiffness and bearing capacity, which can be applied in larger spans and can reduce cost. To produce two-way composite slabs and further improve the integrity of the two layers, Wu Fangbo $[8,9]$ and Zhou Youxiang [10] proposed the use of solid and hollow composite slabs with precast, prestressed ribbed bottom panels, respectively. The precast bottom panels and their composite slabs are shown in Fig. (1). A row of inverted ribs, on which rectangular openings are set, is located in the middle of the precast bottom panel of a solid composite slab (Fig. (1). (a1)).
Following the assembly of the bottom panel, transverse reinforcements can be arranged in the rectangular openings, and a two-way solid composite slab that has good integrity is formed after the cast-in-place concrete is poured and hardened (Fig. (1). (a2)). A double-rib precast bottom panel is applied in hollow composite slabs (Fig. (1). (b1)). Each side of the bottom panel contains a row of inverted ribs with rectangular openings. Lightweight materials can be placed between the two rows of ribs during construction. Following assembly, transverse reinforcements can be arranged in the openings and a two-way hollow composite slab that has good integrity is formed after solidification of the cast-inplace concrete (Fig. (1). (b2)). The applicable spans of both composite slabs mentioned above are generally less than 8 $\mathrm{m}$. One reason for the limited span is that the prestressing wires in precast bottom panels provide most of the reinforcement of a composite slab; as a result, as the span of a composite slab increases, the amount of prestressing in the bottom panel must be increased, which leads to the excessive elastic compression and creeping loss of the prestress. Another reason is that the flexural crack strain of an ordinary concrete is relatively low, so the crack width and deflection most likely cannot satisfy the serviceability requirements. To avoid these problems, we proposed using reactive powder concrete (RPC) instead of ordinary concrete to manufacture the precast, prestressed ribbed bottom panels mentioned above.

RPC is a relatively new cement matrix composite that was invented in the 1990's [11, 12]; RPC has ultra-high mechanical properties (the compressive strength is generally in the range of 100-230 MPa) and superior durability [13, 14], and it can be used as an excellent building material. Currently, RPC is used in many types of construction, including 


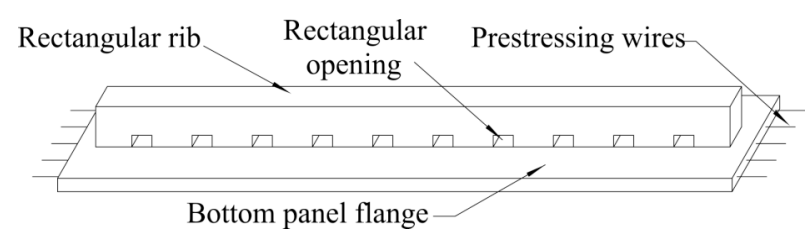

(a1) Single-rib precast bottom panel

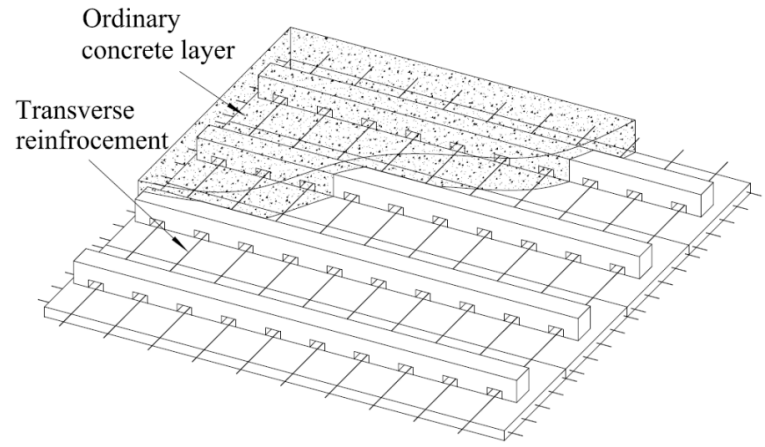

(a2) Solid composite slab

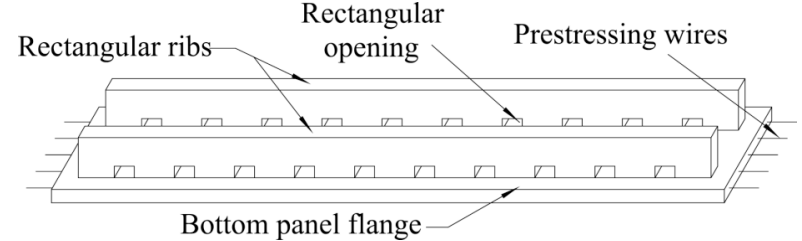

(b1) Double-rib precast bottom panel

Ordinary

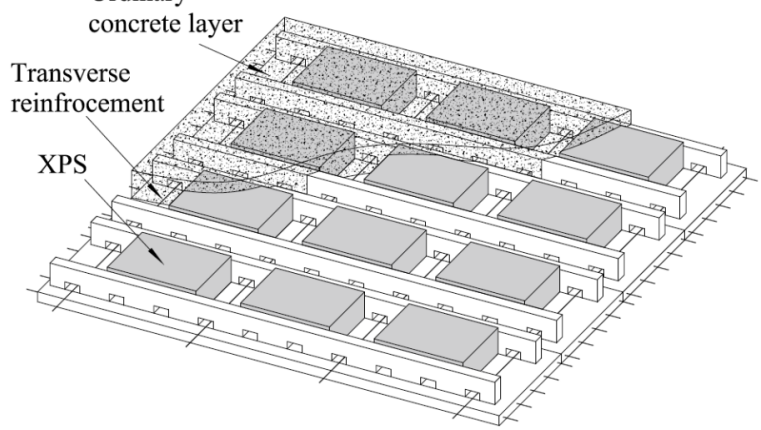

(b2) Hollow composite slab

Fig. (1). Precast ribbed bottom panels and composite slabs.

Table 1. Specimen parameters.

\begin{tabular}{|c|c|c|c|c|c|c|}
\hline Specimens & Number of Prestressing Wires & Calculation Span/mm & $\mathbf{b} / \mathbf{m m}$ & $\mathbf{b}_{\mathbf{1}} / \mathbf{m m}$ & $\mathbf{h} \mathbf{m} \mathbf{m m}$ & $\mathbf{h} / \mathbf{m m}$ \\
\hline \hline B1 & 4 & 2400 & 100 & - & 70 & 110 \\
\hline B2 & 7 & 2400 & 110 & - & 110 & 150 \\
\hline B3 & 7 & 2400 & 100 & 320 & 90 & 130 \\
\hline B4 & 10 & 2400 & 110 & 310 & 110 & 150 \\
\hline
\end{tabular}

Table 2. Specimen parameters.

\begin{tabular}{|c|c|c|c|c|c|c|}
\hline Cement & SF & GBFS & Quartz sand & Superplasticizer & W/B & $\begin{array}{c}\text { Steel fibre } \\
\text { (by Volume) }\end{array}$ \\
\hline \hline 1 & 0.30 & 0.15 & 1.20 & 0.04 & 0.22 & 0.02 \\
\hline
\end{tabular}

bridges [15], factory buildings [16], ocean engineering, and rehabilitation [17]. At the serviceability limit state and the ultimate limit state, the stress of the RPC in the tension zone of the flexural members should not be neglected [18]. Therefore, it is necessary to study the flexural behaviour of these members, including the distribution and development of cracks, the development of the calculation methods of the cracking moment, the flexural stiffness, and the normal section bearing capacity.

\section{EXPERIMENTAL DETAIL}

\subsection{Specimen Design}

Four precast, prestressed ribbed RPC bottom panels were designed and fabricated, of which B1 and B2 were single-rib precast bottom panels and B3 and B4 were double-rib precast bottom panels. Each of the specimens had a length of $2600 \mathrm{~mm}$, and the width and thickness of the precast bottom panel's flange was $500 \mathrm{~mm}$ and $40 \mathrm{~mm}$, respectively. The size of each of the rectangular openings in the inverted ribs was $75 \mathrm{~mm} \times 25 \mathrm{~mm}$, and the spacing was $125 \mathrm{~mm}$. Pre- tensioned technology was used to produce the precast bottom panel, and the prestressing wires were located at the middle of the precast bottom panel's flange. The the parameters are presented in Table $\mathbf{1}$ and details of specimens are shown in Fig. (2).

\subsection{Materials}

The cementitious materials used in this paper are as follows: P.O 42.5 Portland cement (Chinese code, standard compressive $>42.5 \mathrm{MPa}$ at the age of 28 days). The silica fume (SF) $\mathrm{SiO}_{2}$ content exceeds $92 \%$ and has a specific surface area of $20600 \mathrm{~m}^{2} / \mathrm{kg}$. The granulated blast furnace slag (GBFS) has a specific surface area of $475 \mathrm{~m}^{2} / \mathrm{kg}$. Quartz sand: particles of fineness of 70 holes and 140 holes were mixed in a ratio of $1: 1$. Superplasticizer: polycarboxylate was used as a superplasticizer in the RPC mixes. Copperized steel fibres that were $13 \mathrm{~mm}$ in length and $0.22 \mathrm{~mm}$ in diameter were used. The specimens remained in the formwork for $24 \mathrm{~h}$ and were autoclaved at $90-95^{\circ} \mathrm{C}$ for $12 \mathrm{~h}$ to accelerate the curing after demoulding as presented in Table 2. 


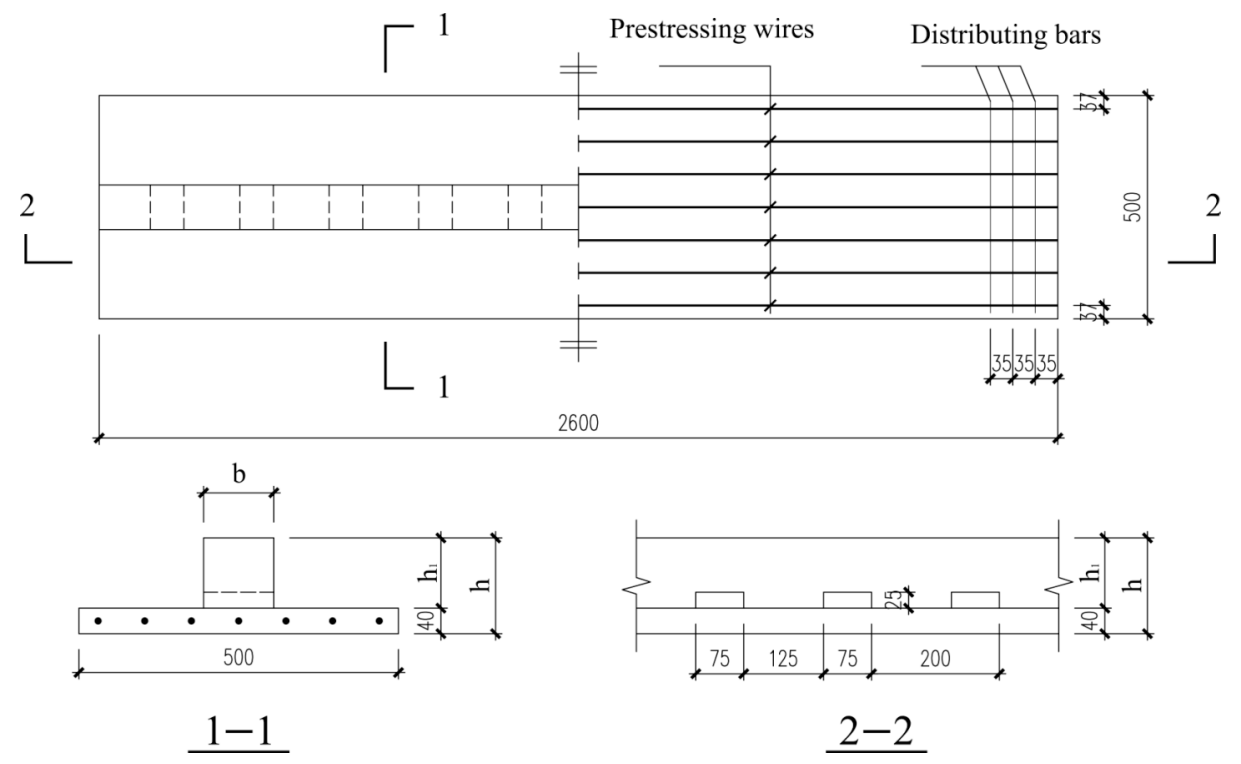

(a) Single-rib precast bottom panel
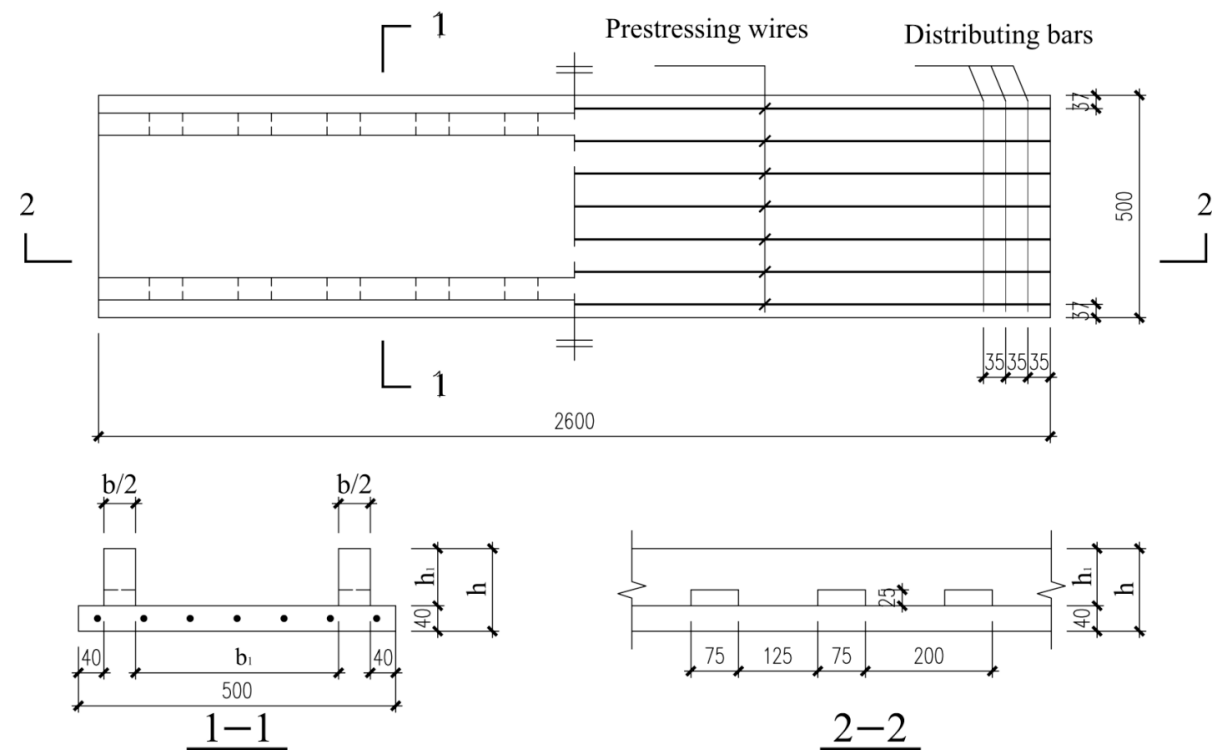

(b) Double-rib precast bottom panel

Fig. (2). Details of the specimens.

Table 3. Mechanical characteristics of RPC in specimens.

\begin{tabular}{|c|c|c|c|c|}
\hline Specimen & B1 & B2 & B3 & B4 \\
\hline \hline Compressive strength $/ \mathrm{MPa}$ & 102.6 & 105.3 & 105.3 & 110.4 \\
\hline Axial tensile strength $/ \mathrm{MPa}$ & 5.0 & 5.1 & 5.1 & 5.5 \\
\hline
\end{tabular}

Note: the RPC elastic modulus was $41.2 \mathrm{GPa}$, and the RPC compressive strain corresponding to the peak stress was $3560 \times 10^{-6}$.

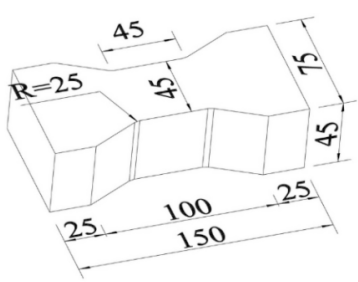

Fig. (3). RPC dumbbell-shaped specimen.
The specimens used for the compression tests were 70.7 $\mathrm{mm} \times 70.7 \mathrm{~mm} \times 228 \mathrm{~mm}$ prisms, and dumbbell-shaped (shown in Fig. (3) specimens were used for the axial tensile tests. The mechanical characteristics of the RPC used in the specimens is presented in Table 3 .

The equation of the compressive stress-strain relationship is given by Equation (1): 


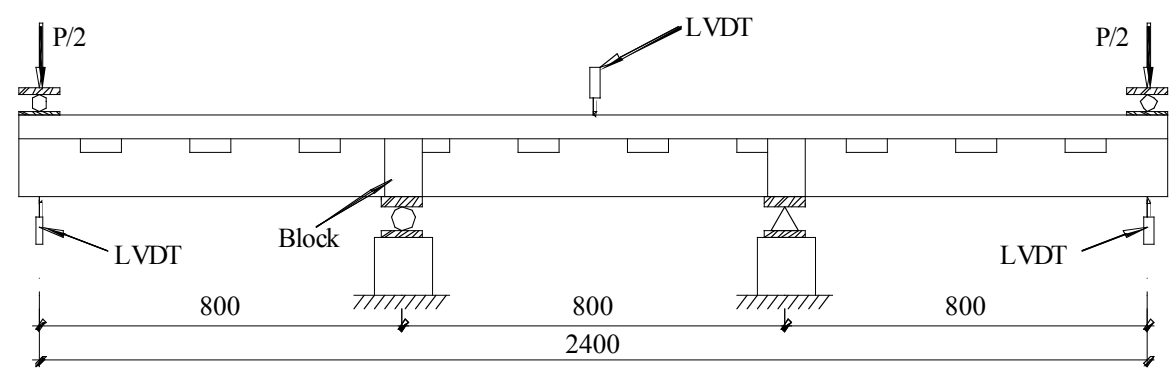

Fig. (4). Experimental device.

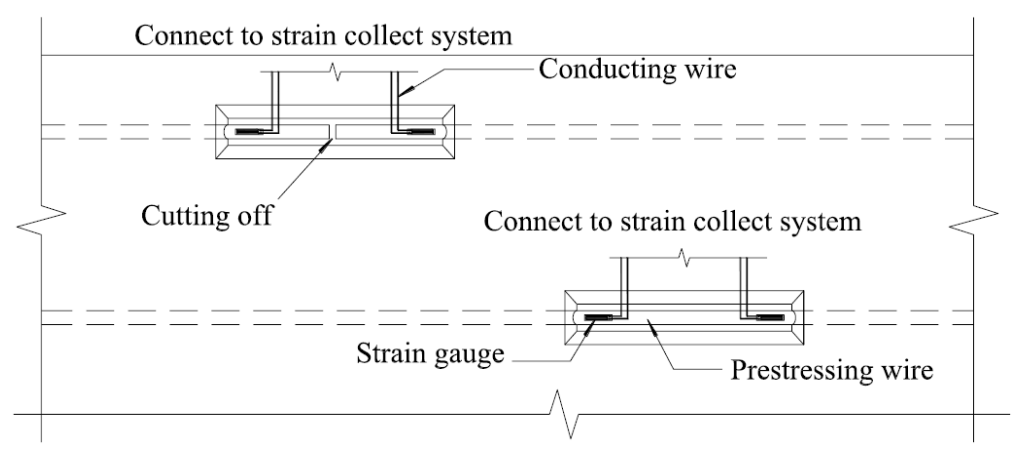

Fig. (5). Measurement of the effective prestress.

$$
\sigma / f_{\mathrm{c}}=\left\{\begin{array}{l}
1.55 \frac{\varepsilon}{\varepsilon_{0}}-1.2\left(\frac{\varepsilon}{\varepsilon_{0}}\right)^{4}+0.65\left(\frac{\varepsilon}{\varepsilon_{0}}\right)^{5} \\
\frac{\frac{\varepsilon}{\varepsilon_{0}}}{6\left(\frac{\varepsilon}{\varepsilon_{0}}-1\right)^{2}+\frac{\varepsilon}{\varepsilon_{0}}}
\end{array}\right.
$$

where $\sigma$ is the compressive stress of the RPC prism; $f_{\mathrm{c}}$ is the compressive strength of the RPC prism; $\varepsilon$ is the compressive strain of the RPC prism; and $\varepsilon_{0}$ is the compressive strain corresponding to the peak stress of RPC.

The reinforcement in the specimens consisted of low relaxation spiral ribbed wires with an elastic modulus of 193 $\mathrm{GPa}$, a strength of $1,588 \mathrm{MPa}$ and a yield strength of 1,451 $\mathrm{MPa}$. The controlled stress for the stretching was 1,020 MPa.

\subsection{Experimental Device}

Specimens were simply supported and tested under twoconcentrated line loads applied at the middle-third of the slabs. To conveniently observe the cracks, the bottom faces of the specimens were oriented upward. To avoid the shear lag effect [19], rigidity blocks were used to level the ribs and flange of each of the specimens. The mid-span deflection was monitored using linear variable differential transformers (LVDTs). Resistance strain gauges were continuously attached at the top of ribs and the bottom surface of specimens of the pure bending section; the experimental device is shown in Fig. (4). At each level of load, the width of each crack at the intersection points with prestressing wires were monitored using a crack-width measurement instrument $(0.002 \mathrm{~mm})$, and the new cracks were marked.

\subsection{Measurement of the Effective Prestress}

To accurately determine the effective prestress of the prestressing wires in the specimens, the bottoms of the ribbed RPC bottom panels (which were fabricated under the same conditions) were grooved to expose the prestressing wires and resistance strain gauges were attached, as shown in Fig. (5). The changes in strain were measured by a strain collection system, and then, the effective prestress in the prestressing wires was calculated.

\section{STRUCTURAL RESPONSE}

The cracking moments of B1, B2, B3 and B4 were 7.67 $\mathrm{kN} \cdot \mathrm{m}, 20.26 \mathrm{kN} \cdot \mathrm{m}, 14.90 \mathrm{kN} \cdot \mathrm{m}$ and $25.11 \mathrm{kN} \cdot \mathrm{m}$, respectively. The first crack of each of the specimens appeared at the section with the opening. The cracks extended and widened with loading, and some of the cracks extended to the upper face of the flange of each specimen; however, no crack was found on the ribs. Cracks disappeared after extending across some distance and then randomly appeared again at a nearby location and continued to extend in the same direction. The cracks on the bottom face of the flange of each specimen were fine, dense and discontinuous, and no consistent crack spacing was observed. The crack width was obviously narrower than that of an ordinary concrete flexural member: at the mid-span moment of 0.95 times the ultimate bending moment $\left(M_{\mathrm{u}}\right)$, the observed maximum crack width was $0.2 \mathrm{~mm}$. New cracks were constantly emerging until the ultimate bending moment; the crack patterns of the pure bending section on the bottom face of specimens are shown in Fig. (6).

The mid-span load-deflection curves of all of the specimens are shown in Fig. (7). The mid-span deflections were approximately linear with the load before cracking and became larger gradually after cracking. When the load ex- 


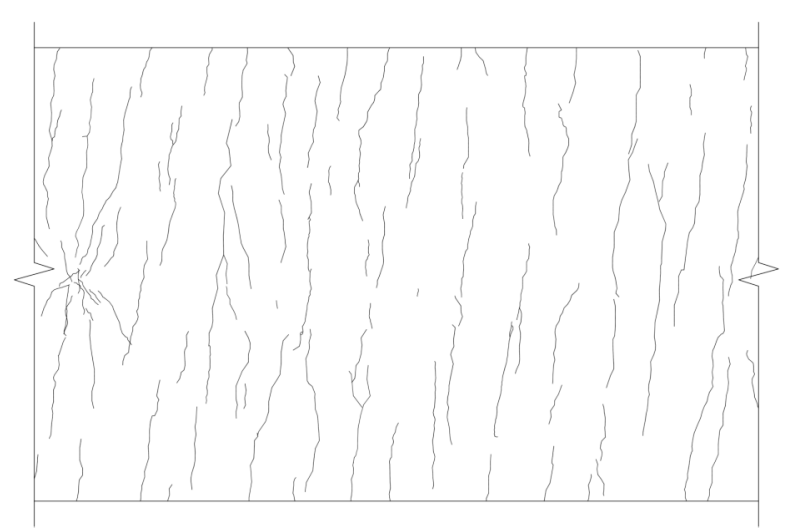

(a) B1

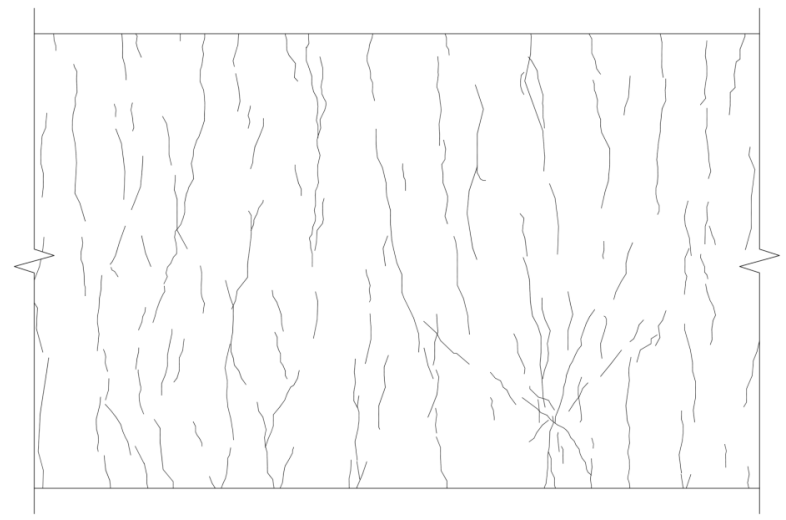

(c) B3

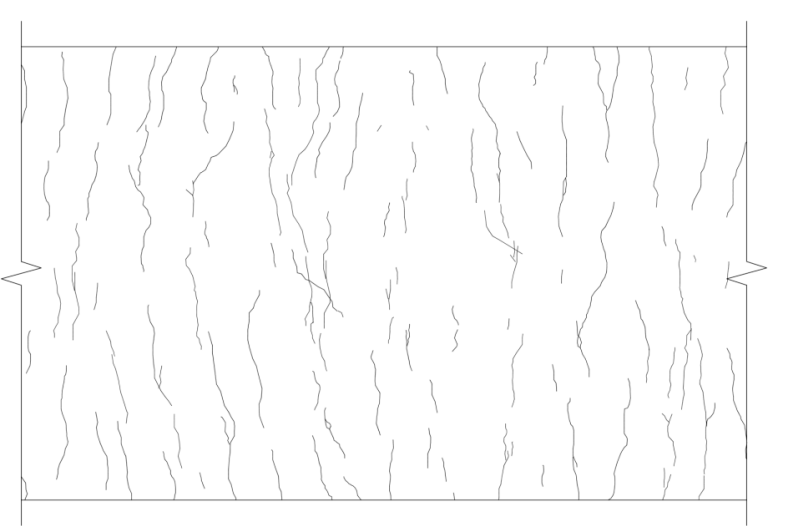

(b) B2

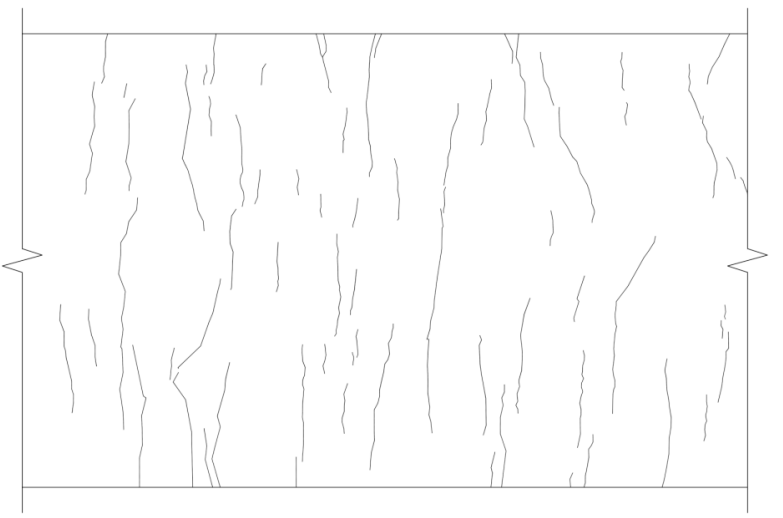

(d) B4

Fig. (6). Crack patterns on the bottom face of the specimens.

ceeded $0.8 M_{\mathrm{u}}$, the mid-span load-deflection curves tended to be horizontal, and failure occurred due to the crushing of the RPC on the top of rib, while the prestressing wires did not yield. The ultimate bending moments of B1, B2, B3 and B4 were $21.56 \mathrm{kN} \cdot \mathrm{m}, 54.80 \mathrm{kN} \cdot \mathrm{m}, 33.67 \mathrm{kN} \cdot \mathrm{m}$ and $52.10 \mathrm{kN} \cdot \mathrm{m}$, respectively. The crushed area of the RPC was limited to the section of the rectangular opening for $\mathrm{B} 1$; however, no relationship with the section of rectangular openings was found for the other specimens. Only one of the ribs failed for specimens B3 and B4. The RPC compressive strain on the top of the rib was found to increase approximately linearly with loading before cracking and to increase gradually after cracking, and the RPC compressive strain was found to increase substantially while approaching failure. The RPC compressive strain on the top of the rib was approximately $5500 \times 10^{-6}$ at the moment before failure occurred, which is consistent with the result of the RPC beam [20]. All of the specimens exhibited the over-reinforced failure mode behaviour. In the type of bottom panel considered here, the prestressing wires are the major reinforcement of the composite slabs in practical engineering. When such a bottom panel is at the ultimate limit state, the compressive area of concrete is much greater than that of the RPC rib; therefore, this type of bottom panel without composite concrete layer generally exhibits over-reinforced failure mode behaviour.

\section{RESULTS AND DISCUSSION}

The section with openings was chosen as the calculating section in this paper because it is the weakest section of a precast, prestressed ribbed RPC bottom panel.

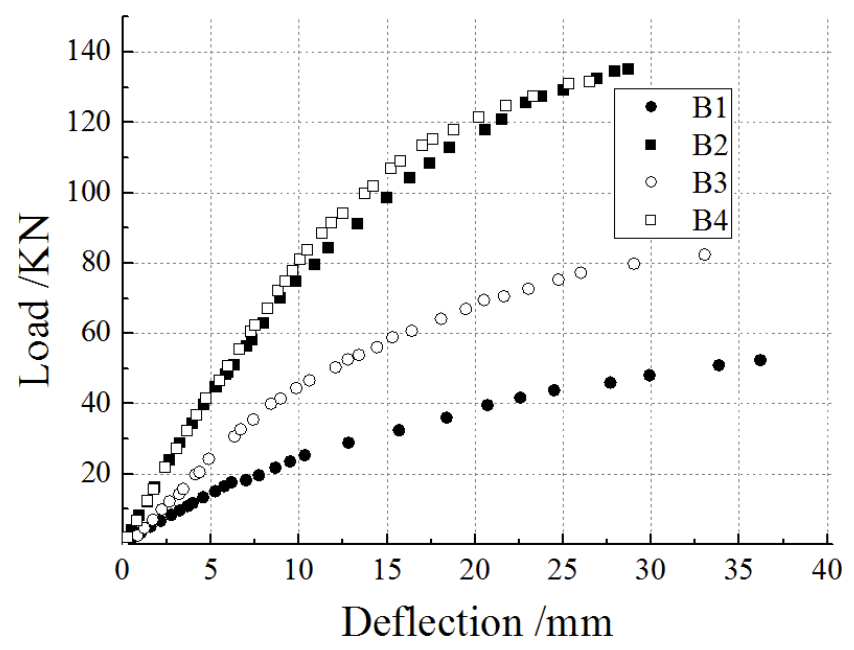

Fig. (7). Mid-span load-deflection curves.

\subsection{Effective Stress in the Prestressing Wires}

The experimental results indicated that the average effective prestress in the prestressing wires of B1, B2, B3 and B4 under no-load conditions were 656.6 MPa, $627.4 \mathrm{MPa}, 627.4$ $\mathrm{MPa}$ and 555.4 MPa, respectively. The calculations in the elastic analysis determined that the RPC compressive stress on the top of the ribs for B1, B2, B3, and B4 were $6.13 \mathrm{MPa}$, $9.46 \mathrm{MPa}, 9.79 \mathrm{MPa}$, and $11.82 \mathrm{MPa}$, respectively, and the stress levels $\left(\sigma_{\mathrm{pc}} / f_{\mathrm{cR}}\right)$ for $\mathrm{B} 1, \mathrm{~B} 2, \mathrm{~B} 3$, and $\mathrm{B} 4$ were 0.059 , $0.090,0.093$, and 0.107 , respectively. 


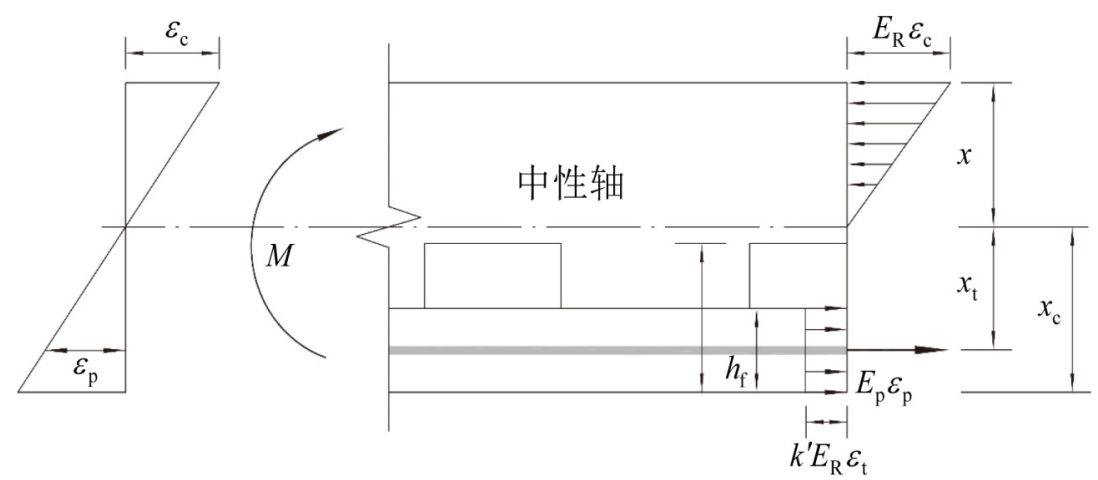

Fig. (8). Stress and strain distributions at the cracked section.

\subsection{Cracking Moment}

The flexural cracking tensile strains of B1, B2, B3 and B4 were $458 \times 10^{-6}, 525 \times 10^{-6}, 545 \times 10^{-6}$ and $577 \times 10^{-6}$, respectively, which were much greater than the strain corresponding to the RPC peak tensile stress [21]. Under the cracking moments of the specimens, the compressive strains of RPC on the top of ribs are relatively small and in the elastic region, but the part of the RPC in the tension zone became plastic. To calculate the cracking moment of specimen, the plastic influence coefficient of the section modulus $\gamma$ was introduced. According to reference [22], $\gamma$ can be calculated as follows:

$\gamma=\frac{\frac{M_{\mathrm{cr}}}{W_{0}}-\sigma_{\mathrm{pc}}}{f_{\mathrm{tR}}}$

where $M_{\mathrm{cr}}$ is the cracking moment and $W_{0}$ is the transformed elastic section modulus at the extreme tension fibre (the elastic modulus ratio of prestressing wires to RPC is $\left.\alpha_{\mathrm{E}}=E_{\mathrm{p}} / E_{\mathrm{R}}=193000 / 41200=4.68\right)$. Based on the experimental data, $\gamma$ of B1, B2, B3 and B4 was 1.24, 1.37, 1.30 and 1.51, respectively.

The bond between prestressing wires and RPC can inhibit cracking; therefore, $\gamma$ increased with the increase of prestressing wire amount. Fitting the results generated Equation (3).

$$
\gamma=24.75 \rho_{\mathrm{te}}+1.02
$$

where $\rho_{\text {te }}$ is the ratio of the area of the prestressing wires to the area of the precast, prestressed ribbed RPC bottom panels' flange. The mean ratio of fitted values to experimental derived values of $\gamma$ is 1.01 , and the coefficient of variation is 0.03 .

\subsection{Deflection Calculation}

The flexural stiffness of all specimens decreased with the increase of the mid-span moment. Under the cracking moment, the flexural stiffness values of B1, B2, B3 and B4 were $0.84 E_{\mathrm{R}} I, 0.84 E_{\mathrm{R}} I, 0.85 E_{\mathrm{R}} I$ and $0.88 E_{\mathrm{R}} I$, respectively, which were consistent with that of an ordinary concrete flexural member [22]. To simplify the calculation, $0.85 E_{\mathrm{R}} I$ was taken as the flexural stiffness of the specimens before cracking occurred.

In the post-cracking stage, based on plane cross-section assumption, the height of the neutral axis can be calculated according to the data measured by resistance strain gauges attached at the top of ribs and the bottom of the specimens. For the mid-span moment between $M_{\mathrm{cr}}-0.8 M_{\mathrm{u}}$, the heights of the neutral axis of the specimens remain approximately constant. The mean heights of the neutral axis of B1, B2, B3 and B4 were $34.8 \mathrm{~mm}, 65.9 \mathrm{~mm}, 53.7 \mathrm{~mm}$ and $62.3 \mathrm{~mm}$, respectively. The formula to calculate the mean height of the neutral axis in post-cracking stage $\left(M_{\mathrm{cr}}-0.8 M_{\mathrm{u}}\right)$ was determined by fitting to be the following:

$x_{\mathrm{c}}=91.2 \frac{A_{\mathrm{r}}}{A_{\mathrm{f}}}+22.1$

where $A_{\mathrm{r}}$ is the cross-sectional area of ribs without opening and $A_{\mathrm{f}}$ is the cross-sectional area of the flange of the specimen. The mean ratio of the fitted values to the experimentally derived values of the height of the neutral axis is 1.0, and the coefficient of variation is 0.04 .

To consider the tensile stress of RPC at a cracked section, the RPC tensile stress of the precast bottom panel flange is assumed to be uniformly distributed, the reduction coefficient of the RPC elastic modulus $\left(k^{\prime}\right)$ is introduced, and the RPC tensile stress on the ribs is assumed to be negligible. The post-cracking flexural stiffness model of the specimens is shown in Fig. (8). When the neutral axis passes through the openings and above the openings, the moments of inertia $\left(I_{\mathrm{cr}}\right)$ at the cracked sections can be calculated using Equations (5-1). and (5-2).

$$
\begin{aligned}
& I_{\mathrm{cr}}=\frac{b_{\mathrm{r}}\left(x^{3}-x^{3}\right)}{3}+\alpha_{\mathrm{E}} A_{\mathrm{p}} x_{\mathrm{t}}^{2}+k^{\prime} b h_{\mathrm{f}} x_{\mathrm{t}}^{2} \\
& I_{\mathrm{cr}}=\frac{b_{\mathrm{r}} x^{3}}{3}+\alpha_{\mathrm{E}} A_{\mathrm{p}} x_{\mathrm{t}}^{2}+k^{\prime} b h_{\mathrm{f}} x_{\mathrm{t}}^{2}
\end{aligned}
$$

where $x^{\prime}$ is the distance from the neutral axis to the top of the openings.

The effective moment of inertia can be calculated using Equation (6). 
$I_{\mathrm{e}}=\left(\frac{M_{\mathrm{cr}}}{M}\right)^{3} I_{\mathrm{g}}+\left[1-\left(\frac{M_{\mathrm{cr}}}{M}\right)^{3}\right] I_{\mathrm{cr}}$

where $I_{\mathrm{g}}=0.85 I$.

On the basis of mechanics knowledge, the post-cracking deflection of mid-span can be calculated as follows:

$\delta=\frac{23 p l^{3}}{1296 E_{\mathrm{R}} I_{\mathrm{e}}}$

According to the analysis, it can be determined that $k^{\prime}=0.35$. The calculated flexural stiffness $\left(\delta^{\mathrm{c}}\right)$ agreed well with the experimentally derived flexural stiffness $\left(\delta^{\mathrm{t}}\right)\left(M_{\mathrm{cr}^{-}}\right.$ $\left.0.8 M_{\mathrm{u}}\right), \delta^{\mathrm{c}} / \delta^{\mathrm{t}}$ is shown in Fig. (9), for which the mean value is 1.02 , and the coefficient of variation is 0.06 .

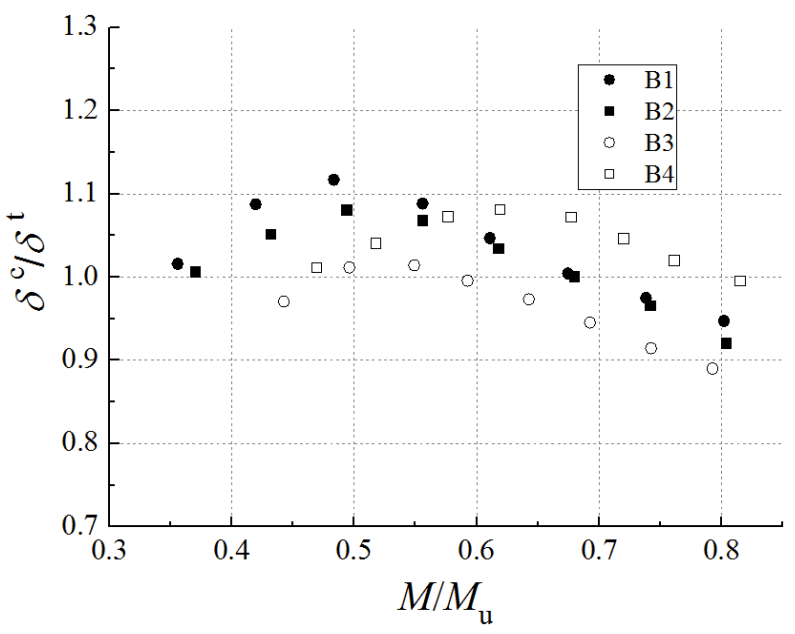

Fig. (9). Ratio of the fitted value to the experimentally derived value of the mid-span deflection.

\subsection{Crack Width Calculation}

Reinforcing steel stress is used as the major variable in most equations [22-24] used for calculating the crack widths in the flexural members. However, the difference between the distance from the neutral axis to the prestressing wires and the distance from the neutral axis to the bottom face was relatively large; therefore, the reinforcing steel stress at the cracked section cannot accurately predict the crack width. In this paper, the cross-sections of specimens were assumed to be elastic, thus enabling the nominal tensile stress $\left(\sigma_{\mathrm{tR}}\right)$ at bottom face to be calculated. The reinforcement ratio should also be considered for the bond between prestressing wires to enable the RPC to inhibit the crack width. For mid-span moment values of $M_{\mathrm{cr}}-0.8 M_{\mathrm{u}}$, the crack width was found to be linear with loading; the fitting result in Equation (8).

$w_{\mathrm{m}}=\left[2.52\left(\sigma_{\mathrm{tR}}-\gamma f_{\mathrm{tR}}\right)+18.35\right] \times 10^{-3}$

The experimental and calculated results of the crack width are shown in Fig. (10). The mean value of the calculated crack width to the measured cracked width was 1.02 , and the coefficient of variation was 0.17 .

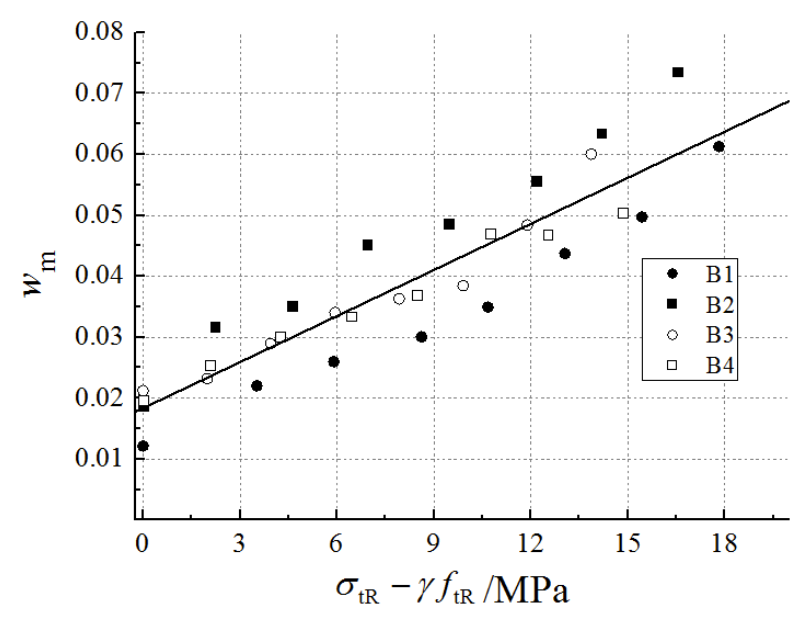

Fig. (10). Measured and calculated values of the average crack width.

The maximum crack width can be obtained by Equation (8). multiplied by an amplification coefficient $\tau_{\mathrm{s}}$ :

$w_{\max }=\tau_{\mathrm{s}} w_{\mathrm{m}}$

The amplification coefficient $\tau_{\mathrm{s}}$ can be determined using the probability distribution of the crack widths. Statistical analysis indicated that for the mid-span moment values in the range of $M_{\mathrm{cr}}-0.8 M_{\mathrm{u}}, w_{\mathrm{i}} / w_{\mathrm{m}}$ follows the lognormal distribution, with a mean $(\mu)$ and standard deviation $(\sigma)$ of 0.065 and 0.440 , respectively ( $w_{\mathrm{i}}$ is the crack width at a certain load level, $w_{\mathrm{m}}$ is the average crack width at the load level). The frequency distribution and probability density curve of $w_{\mathrm{i}} / w_{\mathrm{m}}$ are shown in Fig. (11). The calculations indicated that the amplification coefficient $\left(\tau_{\mathrm{s}}\right)$ of the crack width with $95 \%$ confidence is 1.9 . As a result, the maximum crack width with $95 \%$ confidence can be calculation using Equation (10).

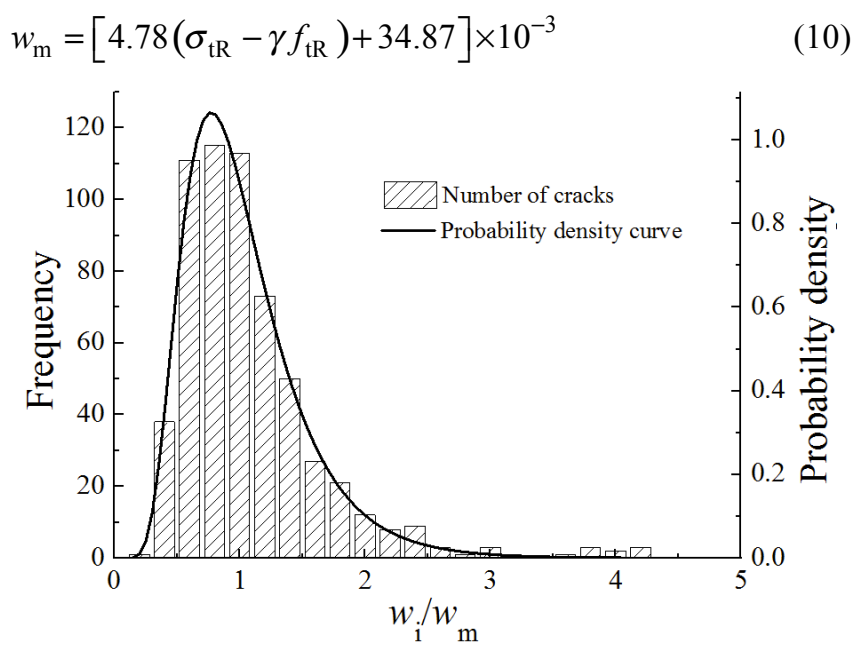

Fig. (11). Crack width frequency distribution.

\subsection{Normal Section Bearing Capacity}

In contrast with an ordinary concrete flexural member, the effect of RPC tensile stress should be considered at the 


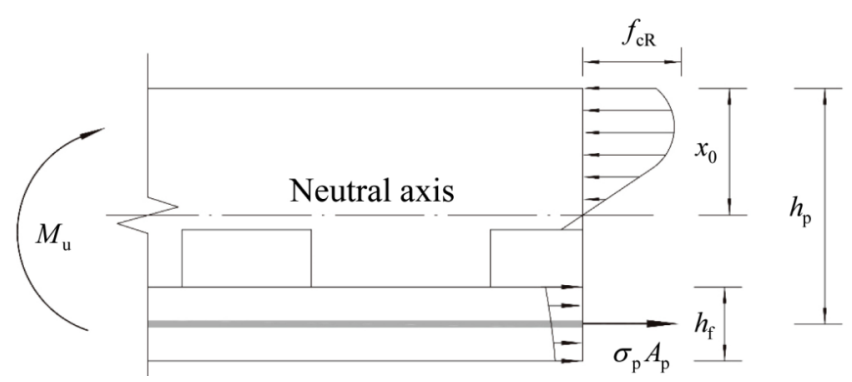

(a) Actual stress distribution

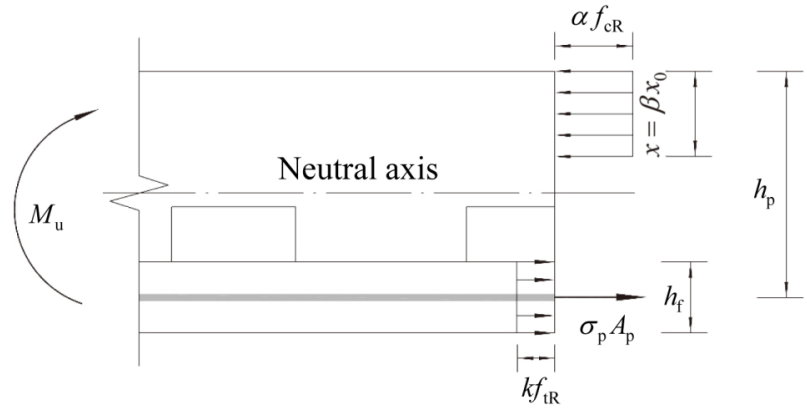

(b) Equivalent stress distribution

Fig. (12). Stress distribution on a cross section of the specimen at the ultimate moment.

ultimate moment [20]. The failure mode of all specimens was crushing of the RPC on the top of rib without the yielding of the prestressing wires; therefore, the normal section bearing capacity should be calculated by the method of an over-reinforced flexural member.

To determine the normal section bearing capacity of a precast, prestressed ribbed RPC bottom panel, the follows assumptions are made: 1, the plane section remains plane after bending; 2, the tensile stress of the RPC in the bottom panel flange has a rectangular distribution with a height of $k f_{\mathrm{tR}}$; and 3 , the tensile stress of the RPC in the rib is neglected.

To simplify the calculation, the actual stress distribution can be simplified by an equivalent rectangular stress diagram (the remaining compressive resultant force and its applied point constant), as shown in Fig. (12). Based on the RPC compressive stress-strain relationship, the equivalent coefficients $\alpha$ and $\beta$ can be determined as 0.9 and 0.77 [20], respectively. For the strain of section that remains plane after bending, when the yielding of prestressing wires and the failure of RPC occurred simultaneously, the relative depth of limiting compression zone $\xi_{\mathrm{b}}$ can be calculated according to following equation:

$$
\xi_{\mathrm{b}}=\frac{x_{\mathrm{b}}}{h_{\mathrm{p}}}=\frac{\beta_{1}}{1+0.002 / \varepsilon_{\mathrm{cu}}+\left(f_{\mathrm{py}}-\sigma_{\mathrm{p} 0}\right) / E_{\mathrm{s}} \varepsilon_{\mathrm{cu}}}
$$

where $h_{\mathrm{p}}$ is the effective depth of the section, $f_{\mathrm{py}}$ is the yield strength of the prestressing wires, $\sigma_{\mathrm{p} 0}$ is the stress in the prestressing wire while the normal stress of RPC at the depth of prestressing wire is equal to 0 , and $\varepsilon_{\mathrm{cu}}$ is the RPC ultimate strain under non-uniform compressive $\left(5500 \times 10^{-6}\right)$.

The values of $\xi_{\mathrm{b}}$ of $\mathrm{B} 1, \mathrm{~B} 2, \mathrm{~B} 3$ and $\mathrm{B} 4$ were 0.368 , $0.365,0.366$ and 0.356 , respectively. To simplify the calculation and provide a margin of safety, the value of $\xi_{\mathrm{b}}=0.356$ was chosen. Based on moment equilibrium, the normal section bearing capacity is calculated using Equation (12).

$$
M_{\mathrm{u}}=\alpha_{1} f_{\mathrm{cR}} b h_{\mathrm{p}}^{2} \xi_{\mathrm{b}}\left(1-0.5 \xi_{\mathrm{b}}\right)
$$

The calculated value of the normal section bearing capacity $M_{\mathrm{u}}^{\mathrm{c}}$ and the experimentally derived value $M_{\mathrm{u}}^{\mathrm{t}}$ were found to agree well: the mean of $M_{\mathrm{u}}^{\mathrm{c}} / M_{\mathrm{u}}^{\mathrm{t}}$ is 0.99 and the coefficient of variation is 0.04 .

\section{CONCLUSION}

This paper introduced precast, prestressed single-rib and double-rib precast RPC bottom panels and investigated their flexural behaviour under flexural load. Based on the results, the following conclusions can be derived.

1) For a steel fibre mix proportion of $2 \%$ by volume, the RPC ultimate strain under non-uniform compressive is $5500 \times 10^{-6}$, which is greater than that of ordinary concrete (approximately $3300 \times 10^{-6}$ ); the RPC bend cracking tensile strain is $458 \times 10^{-6}-577 \times 10^{-6}$, which is greater than that of ordinary concrete $\left(80 \times 10^{-6}-120 \times 10^{-6}\right)$.

2) The proposed calculation formula for cracking moment considers the reinforcement ratio when calculating the plastic influence coefficient of the section modulus.

3) The cracks at the bottom of a precast, prestressed ribbed RPC bottom panel were fine, dense and discontinuous, and no consistent crack spacing was found. The proposed calculation formula used the RPC nominal tensile stress as major variable and considered the effect of the reinforcement ratio.

4) The flexural stiffness gradually reduced with loading. Under the cracking moment of the specimens, the flexural stiffness was determined to be $0.85 E_{\mathrm{R}} I$. For values of the mid-span moment in the range of $M_{\mathrm{cr}} \sim 0.8 M_{\mathrm{u}}$, the effect of the RPC tensile stress should be considered when calculating the flexural stiffness, and the RPC reduction coefficient of the elastic modulus $k^{\prime}=0.35$ should be used in the calculation.

5) In a precast, prestressed ribbed RPC bottom panel, the primary bearing reinforcements of the composite slab, the specimens exhibited over-reinforced failure mode behaviour. Based on the experimental results, the normal section bearing capacity of this mode was determined.

\section{CONFLICT OF INTEREST}

The authors confirm that this article content has no conflict of interest. 


\section{ACKNOWLEDGEMENTS}

Declared none.

\section{REFERENCES}

[1] A. A. Yee, and D. Hon. "Structural and economic benefits of precast / presstressed concrete construction", PCI Journal, vol. 46, pp. $34-42,2001$.

[2] J.G. Hou, and C. X. He. "Composition plane behaviour of prestressed composite slab". Journal of WuHan University of Hydraulic and Electrical Engineering, vol. 26, pp. 307-316, 1993

[3] E.N.B.S. Julio, A. B. Fernando, B. V. D. Silva, "Concrete-toconcrete bond strength. Influence of the roughness of the substrate surface," Construction and Building Materials, vol. 18, pp. 675681, 2004.

[4] A.I. Tenhovuori, and M.V. Leskela. "Longitudinal shear resistance of composite slab," Construct Steel Research, vol. 46, pp. 238-245, 1998.

[5] M Pentti, and Y Sun. "The longitudinal shear behaviour of a new steel sheeting profile for composite floor slab," Journal of Constructional Steel Research, vol. 49, pp. 117-128, 1999.

[6] W.A. Thanoon, Y Yardim, M.S. Jaafar, and J. Noorzaei, "Structural behaviour of ferrocement-brick composite floor slab panel," Construction and Building Materials, vol. 24, pp. 2224-2230, 2010.

[7] Q.Q. Jiang, X.M. Wang, H.C. Liu, and S.C. Huang, "Calculation method of composite slab with inverted-T bottom panel," Journal of Central South University and Technology, vol. 34, pp. 567-570, 2003.

[8] F.B. Wu, L Chen, and Y.M. Liu. "Experiment on prestressed concrete hollow-core composite slabs". Journal of Architecture and Civil Engineering, vol. 25, pp. 88-92, 2008.

[9] F.B. Wu, H.L. Huang, W Chen, and X.H. Zhou. "Experimental analysis on the mechanical properties of concrete composite slabs with precast prestressed rectangular rib panels". Journal of Civil, Architectural \& Environmental Engineering. vol. 33, pp. 7-12, 2011.

[10] Y.X. Zhou, and F.P. Wang, "A research on the floor cover of reinforced concrete core clip plank with two-way dense ribs," Journal of Nanhua University, vol. 19, pp. 91-95, 2005.

[11] P. Richard, and M. Cheyrezy, "Composition of reactive powder concretes," Cement and Concrete Research, vol. 25, pp. 1501$1511,1995$.
[12] H Yazıcı, M Yücel, S. Aydın, and A. S. Karabulut, "Mechanical properties of reactive powder concrete containing mineral admixtures under different curing regimes," Construction and Building Materials, vol. 23, pp. 1223-1234, 2009.

[13] A Cwirzen, V Penttala, and C Vornanen, "Reactive powder based concretes: Mechanical properties, durability and hybrid use with OPC," Cement and Concrete Research, vol. 38, pp. 1217-1226, 2008.

[14] N. Roux, C. Andrade, and M.A. Sanjuan, "Experimental study of durability of reactive powder concretes," Journal of Materials in Civil Engineering, vol. 8, pp. 1-6, 1996.

[15] P.Y. Blais, and M. Couture, "Prestressed pedestrian bridge-world's first reactive powder concrete structure," PCI Journal, vol. 44, pp. 60-71, 1999.

[16] C.J. Ao, "Conruction techniques of applying RPC precast units in ex-tension of industrial building," Shanxi Architecture, vol. 31, pp. 127-128, 2005.

[17] B.A. Tayeh, and B.H.A. Bakar, "Utilization of ultra-high performance fibre concrete (UHPFC) for rehabilitation - a review," Procedia Engineering, vol. 54, pp. 525-538, 2013.

[18] A.K. Azad, and I.Y. Hakeem, "Flexural behavior of hybrid concrete beams reinforced with ultra-high performance concrete bars," Construction and Building Materials, vol. 49, pp. 128-133, 2013.

[19] C.Y. Tian, and J.G. Nie, "Shear lag analysis of simply supported composite steel-concrete beams," Journal of Tsinghua University. vol. 45, pp. 1166-1169, 2005.

[20] W.Z. Zheng, L. Li, and S.S. Lu, "Experimental research on mechanical performance of normal section of reinforced reactive powder concrete beam," Journal of Building Structures, vol. 32, pp. 125-134, 2011.

[21] X.Y. Lu, Y. Wang, C.J. Fu, and W.Z. Zheng, "Basic mechanical property indexes of reactive powder concrete," Journal of Harbin Institute of Technology, vol. 46, pp. 1-9, 2014.

[22] Code for Design of Concrete Structures, 7 Vols. People's Republic of China Ministry of Construction, Beijing: 2010.

[23] P. Gergely, and L.A. Lutz, "Maximum crack width in reinforced concrete flexural members," ACI Journal. vol. SP-20, pp. 87-117, 1968.

[24] E.G. Nawy, and P.T. Huang, "Crack and deflection control of pretensioned prestressed beams", PCI Journal, vol. 22, pp. 30-47, 1977. 